\title{
Adsorption of Protein from Several Commercial Lipase Preparations onto a Hollow-Fiber Membrane Module
}

\author{
Victor M. Balcão, Madalena C. Vieira, and F. Xavier Malcata* \\ Escola Superior de Biotecnologia, Universidade Católica Portuguesa, Rua Dr. António Bernardino de Almeida, \\ 4200 Porto, Portugal
}

\begin{abstract}
Ten commercially available crude preparations of lipase from various microbial sources were adsorbed from aqueous buffers at several initial concentrations onto a bundle of hydrophobic hollow fibers made of poly(propylene) at $\mathrm{pH} 7.0$ and $40^{\circ} \mathrm{C}$. The kinetics of adsorption were evaluated from measurements at various times of the protein content of the supernatant sol ution (using BSA as equivalent) in a well-mixed reservoir placed in series with the hollow fiber module. Preliminary tracer experiments have indicated that the module and the tank can be simulated as a system consisting of a plug flow reactor in series with a continuous stirred tank reactor. A mechanistic model based on the hydrodynamic assumptions associated with this system coupled with the postulation of two reversible first-order steps for the adsorption of protein was successfully fitted to the experimental data via nonlinear regression analysis. The statistical significance of the model was checked using tests for lack of fit. This work is useful in predicting the time period required to immobilize a (crude) lipase by adsorption onto a hydrophobic hollow fiber module, a configuration which has proved successful in the recent past for the performance of lipase-catalyzed reactions.
\end{abstract}

\section{Introduction}

Although microporous membranes were initially devised as filtration media, the high ratios of available area (mostly accounted for by the inner surface of the pores) to volume (occupied by the membrane matrix) have permitted their alternative use as an efficient support for enzyme immobilization by either adsorption or covalent attachment.

Enzyme immobilization by physical adsorption traditionally refers to binding of the enzyme via weak attractive forces to an inert carrier which has not been chemically derivatized. Since the carrier is directly involved in binding to the enzyme, its chemical nature, particle size (in the case of granules) or thickness (in the case of membranes), and pore size distribution (especially in the range where pores are large enough to be accessible to enzyme) play important roles (Masoom et al., 1989; Rouxhet, 1990). In general, physical adsorption of an enzyme is achieved by simply contacting the buffered enzyme solution with the carrier, which may require minimal pretreatment such as wetting, washing, and presoaking in the buffered solution (especially when the carrier possesses hydrophobic character) and usually requires minimal post-treatment such as washing out the excess solution containing nonadsorbed enzyme (Masoom et al., 1989; Tramper, 1983). I mmobilization by physical adsorption possesses the advantages that (i) it is easy to perform, (ii) the substrate specificity usually remains unchanged, (iii) it permits regeneration of the carrier with fresh enzyme, and (iv) the immobilization is a lowcost procedure in terms of chemicals required; however, it also possesses the major disadvantage that the binding force between the carrier and the enzyme is weak, leading to potential leakage of the enzyme from the carrier during use (with subsequent loss of catalytic activity and contamination of products) (Bailey and Ollis, 1986). Use of adsorption for enzyme immobilization is often selected when the costs of immobilization are to be kept low, and the support is to be reutilized by reloading with fresh enzyme (Brady et al., 1988).

Adsorption of proteins (including enzymes) at solid/ liquid interfaces is of great technical significance. The fact that lipases are activated by aqueous/hydrophobic interfaces and display usually very little catalytic activity in the absence thereof, as was first reported in the pioneering work by Sarda and Desnuelle (1958), has prompted a number of researchers to experiment with polymeric membranes in attempts to find efficient carriers for lipase. Examples of polymeric materials in membrane form used to immobilize lipases which have been discussed in the literature include poly(propylene) membranes in flat sheet form (Hoq et al., 1985b,c; Malcata et al., 1991; Yamane et al., 1986) and hollow fiber form (Hoq et al., 1985a; Malcata et al ., 1992a-d, 1993a,b), acrylic membranes in flat sheet form (Taylor et al., 1986), cellullose in flat sheet form (Geluk et al., 1992) and hollow fiber form (Pronk et al., 1988; van der Padt et al., 1990), poly(tetrafluoroethylene) (Rucka et al., 1989), and poly(vinyl chloride) (Rucka and Turkiewicz, 1990). Hydrophobic interactions are expected to play a major role in the adsorption of lipases onto hydrophobic membranes especially because lipases possess an unusually high degree of hydrophobicity among enzymes. In particular, dehydration of hydrophobic regions of both protein and sorbent may contribute significantly to the adsorption driving force (Geluk et al., 1992) and preferential adsorp- 


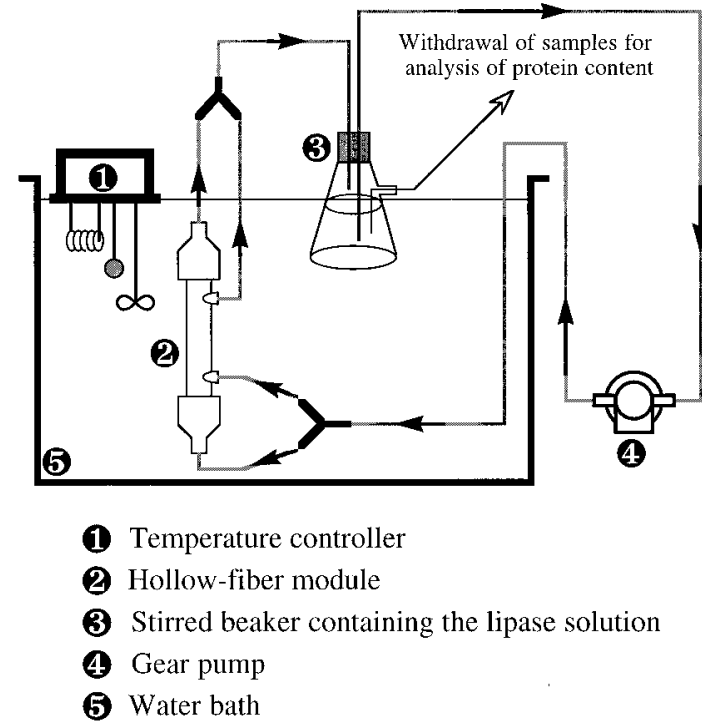

Figure 1. Schematic representation of the experimental setup utilized.

tion of lipase relative to other accompanying proteins in crude preparations (as is the case of most commercial lipase products) onto hydrophobic supports is likely to lead to a partial purification of this enzyme in the adsorbed state (Malcata et al., 1991, 1992a; Rucka and Turkiewicz, 1990).

Although equilibrium data relating the amount of lipase adsorbed to the amount of lipase remaining in the supernatant solution are available for lipases from Aspergillus niger and support of poly(propylene) (Malcata et al., 1992a) and lipase from Candida rugosa and support of cellulose (Pronk et al., 1988), information on the kinetics associated with adsorption processes encompassing lipases is virtually nonexistent to date. It is the purpose of this communication to provide insight into the time-dependent adsorption phenomena of 10 crude, commercial lipases onto a module of hollow fibers made of poly(propylene) with hydrophobic character. This study was developed through sequential steps of (a) obtaining experimental information (at a temperature and $\mathrm{pH}$ which usually provide a good compromise between high activity and high stability of the lipases in the immobilized state thereafter), (b) postulating a mathematical model for adsorption derived from first principles (taking advantage of evidence provided by independently designed hydrodynamic experiments), (c) fitting such a model to adsorption data, and (d) statistically assessing the goodness of the fits obtained therewith.

\section{Materials and Methods}

Experimental Setup. The experimental setup is depicted in Figure 1. A laboratory hollow-fiber module Liqui-Cell X10/240 (Hoechst Celanese, U.S.) with fibers made of hydrophobic poly(propylene) was used in the adsorption experiments. This module is $30 \mathrm{~cm}$ long and has an internal diameter of $2.15 \mathrm{~cm}$. It contains 3000 fibers with nominal length of $23 \mathrm{~cm}$, nominal internal diameter of ca. $240 \mu \mathrm{m}$, nominal thickness of ca. $30 \mu \mathrm{m}$, nominal pore size of ca. $0.2 \mu \mathrm{m}$, and nominal porosity of ca. $60 \%$; these figures lead to nominal total outer surface membrane area of ca. $0.650 \mathrm{~m}^{2}$ and nominal lumen and shell side volumes of ca. 31.2 and $34.7 \mathrm{~cm}^{3}$, respectively. The hollow fibers, manufactured by a process involving stretching of extruded poly(propylene) in a heat tunnel, possess excellent mechanical properties (burst strength of 60 psia, stability up to $75^{\circ} \mathrm{C}$, excellent resistance to acids, bases, ketones, and alcohols, and good resistance to esters, ethers, oils, and hydrocarbons).

The lipases assayed were commercial preparations kindly supplied by AMANO (J apan) and obtained from Candida cylindracea (AY30), Candida lipolytica (L5), Rhizopus delemar (D20), Rhizopus oryzae (F-AP15), Penicillium roqueforti (R10), Penicillium camembertii (G50), Aspergillus niger (A6), Humicola languinosa (CE10), Geotrichum candidum (GC4), and Mucor javanicus (M10) and were used without further purification.

All adsorption experiments were carried out in a constant-temperature bath built in Perspex, equipped with a mechanical agitator and a digital temperature controller (J ulabo, Germany). Absorbance was measured with a Shimadzu UV-265 (J apan) spectrophotometer using disposable 3-mL cuvettes (Kartell, Italy). The refractive index was measured using a thermostated Abbe refractometer 1230 (Atago, Germany). Recirculation of the lipase solutions through the hollow-fiber module was achieved by the action of a high-precision gear pump Ismatec MC-Z (Switzerland). Continuous sampling was achieved using a Bio-Rad fraction collector (Model 2110, U.S.).

Reagents. Powdered Coomassie Brilliant Blue G-250, citric acid, BSA (Albumin Fraction $V$ from bovine blood), ethanol for spectroscopy $(99.9 \% \mathrm{v} / \mathrm{N})$, and orthophosphoric acid were obtained from Merck (Germany). Potassium monohydrogen phosphate, Carmin Indigo, and glycerol were obtained from Sigma (U.S.). Tap water was subjected to successive steps of reverse osmosis, adsorption, deionization, microfiltration, and photo-oxidation in a ELGASTAT UHQ system (England). Fermentation ethanol ( $96 \% \mathrm{v} / \mathrm{v}$ ) was obtained from AGA (Portugal).

Protocols. The Mcl lvane buffer was prepared according to the procedure described elsewhere (Dawson et al., 1969) ( $3.71 \mathrm{~g}$ of citric acid dissolved in $176.5 \mathrm{~mL}$ of water was added to a solution of $37.59 \mathrm{~g}$ of potassium monohydrogen phosphate in $823.5 \mathrm{~mL}$ of water, and the $\mathrm{pH}$ of the resulting buffer was adjusted to 7.0).

The working solution of Coomassie Brilliant Blue G-250 was prepared according to the procedure described elsewhere (Robyt and White, 1990) (100 mg of Coomassie Brilliant Blue G-250 were dissolved in $50 \mathrm{~mL}$ of $99.9 \%$ ethanol and added to $100 \mathrm{~mL}$ of $85 \%$ orthophosphoric acid, and the resulting solution was diluted to $1 \mathrm{~L}$ with water).

Each commercial lipase (in the form of a crude powder) was added to Mcl lvane buffer and diluted as necessary to obtain final solutions in an absorbance range where Beer's law is valid. Aliquots of $0.5 \mathrm{~mL}$ of the crude lipase solutions were added to $4.5 \mathrm{~mL}$ of the solution of Coomassie Brilliant Blue and incubated at room temperature for $5 \mathrm{~min}$, and the absorbance was measured at $595 \mathrm{~nm}$. (This method of quantification, commonly known as the Bradford method, accurately assays protein and is much less susceptible to interfering substances than Lowry or Folin-Lowry methods.) Plain Mcllvane buffer was used as the blank. A calibration curve was prepared using solutions of bovine serum al bumin (BSA) in Mcl lvane buffer at several concentrations in the range $0-400 \mu \mathrm{g} / \mathrm{mL}$, and this calibration curve was used to convert the absorbance reading for each al iquot of crude lipase solution to an equivalent concentration of BSA.

All adsorption experiments were conducted at $40^{\circ} \mathrm{C}$. For each experiment, $200 \mathrm{~mL}$ of a crude lipase solution with a given initial concentration in M cl Ivane buffer was poured into the stirred beaker and recirculated through both the lumen and the shell sides of the fibers at a given flow rate. Aliquots from the beaker were taken regularly and assayed for protein content using the above protocol, 

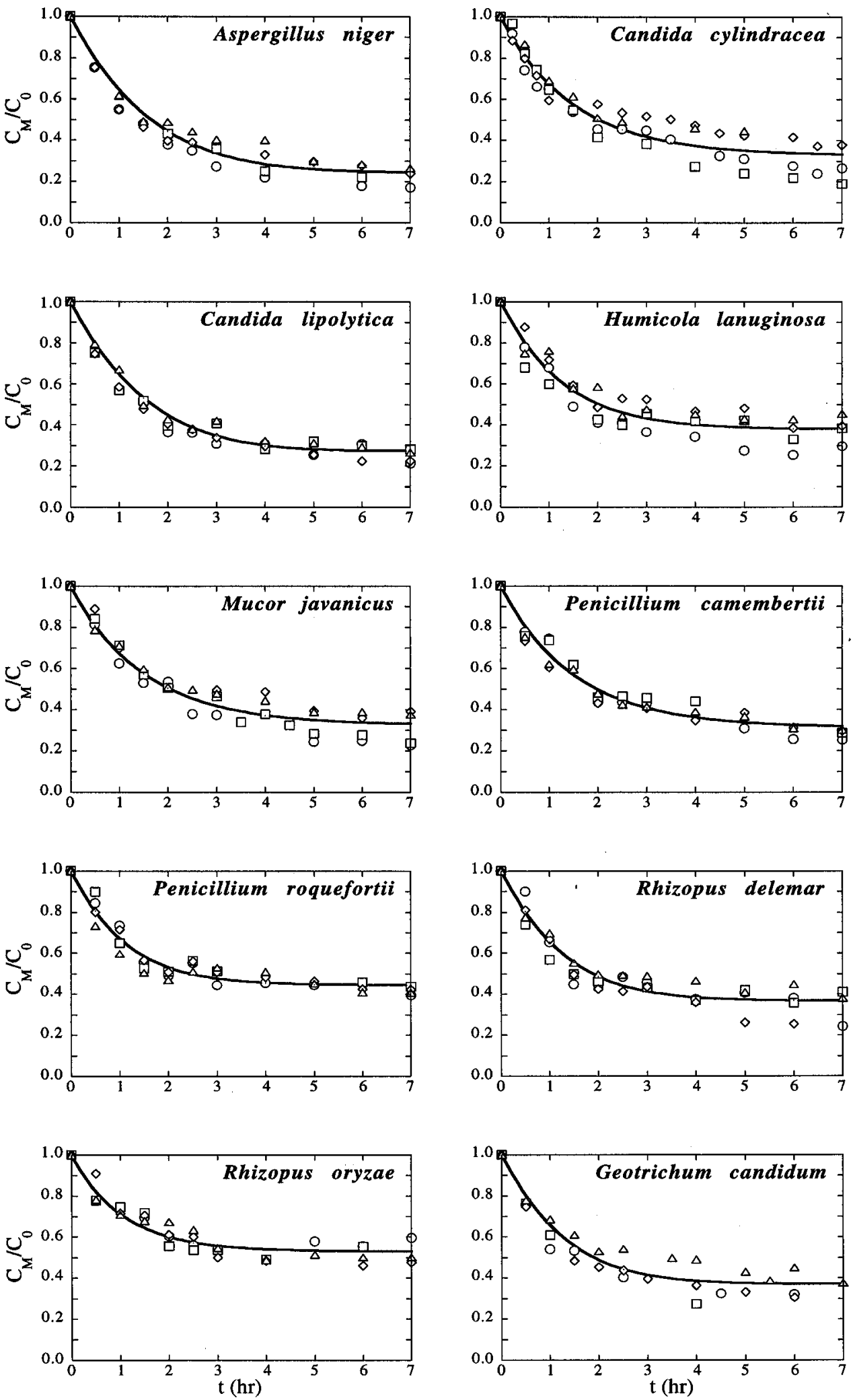

Figure 2. Plots of the normalized concentrations of protein in the supernatant solution versus time (using a recirculation flow rate of $112 \mathrm{~mL} / \mathrm{h}$ ) for the 10 lipases screened. The initial protein concentrations were 48.29, 49.51, 54.88, 39.85, 54.02, 38.07, 69.11, 39.45, 55.43, and $50.74 \mu \mathrm{g} / \mathrm{mL}$ for lipases from A. niger, C. cylindracea, C. li polytica, H. Ianugi nosa, M. javani cus, P. camembertii, P. roquefortii, R. delemar, $R$. oryzae, and G. candidum, respectively $(O) ; 79.81,79.38,76.67,81.72,86.39,71.35,69.88,80.02,88.22$, and $87.88 \mu \mathrm{g} / \mathrm{mL}$, respectively ( $\square)$; 101.68, 104.22, 104.28, 116.45, 114.35, 106.97, $88.22,108.66,118.37$, and 109.50 $\mu \mathrm{g} / \mathrm{mL}$, respectively $(\diamond)$; and 132.67, 139.24, 174.45, 145.94, 150.98, 133.08, 126.90, 132.88, 130.68, and $141.89 \mu \mathrm{g} / \mathrm{mL}$, respectively $(\Delta)$. The theoretical fit is represented by (-).

and the changes in the protein concentration of the supernatant solution were associated with adsorption of such protein onto the hydrophobic membranes. The experimental data pertaining to the adsorption of protein (expressed as equivalent BSA) from the buffered solu- tions of the crude commercial lipases recirculated through the apparatus at a flow rate of $112 \mathrm{~mL} / \mathrm{h}$ are depicted in Figure 2 in the form of normalized concentrations of protein in the supernatant solutions of crude lipase preparations. 
After having performed an adsorption experiment (consisting of adsorbing the lipase from a crude solution with a given initial concentration using a given flow rate over a period of $7 \mathrm{~h}$ ), and prior to the next experiment, the hollow-fiber module was rinsed with the following sequence of liquids: fermentation ethanol for ca. $15 \mathrm{~min}$ (to completely desorb the lipase), water until no ethanol could be detected in the outlet stream (ca. $15 \mathrm{~min}$, in order to strip the ethanol from the pores and concomitantly ensure that these were completely filled with water), and Mcllvane buffer for ca. $15 \mathrm{~min}$ (to create a buffered environment in the module similar to the environment prevailing when the crude lipase solution will be pumped).

The hydrodynamic behaviors of the lumen and the shell sides of the hollow-fiber module, of the hollow-fiber module as a whole, and of the well-stirred beaker containing $200 \mathrm{~mL}$ of water were studied via injection of quick pulses of tracer $(5.0 \mathrm{~mL}$ of a $0.1 \mathrm{~g} / \mathrm{L}$ aqueous solution of Carmin Indigo) at the appropriate inlet stream. When only one of the sides of the hollow-fiber module was tested for its hydrodynamics, the tubing connecting the pump to the other side was kept closed and the liquid in the other side was previously drained (i.e., the other side was maintained full with air); the hydrostatic pressure in the side of interest was carefully kept below the breakthrough pressure at all times so as to avoid bulk permeation of the aqueous solution of tracer through the hydrophobic porous membrane; when the hydrodynamics of the hollow fiber module as a whole were under scrutiny, the aqueous solution containing tracer was pumped through both thelumen and the shell sides at the same time and the fraction of flow through each side was regulated by means of a pair of metallic tweezers applied to the inlet tubing to either side in order to guarantee similar space times. (I deally, two independent positive displacement pumps should be employed rather than a combination of one single pump and a pair of two valves.) Samples were collected from the outlet stream at constant time intervals. These samples were subsequently assayed for tracer concentration by reading their absorbance at a wavelength of $587 \mathrm{~nm}$ using disposable 3-mL cuvettes and converting via the calibration curve previously obtained. Typical results obtained in these tracer experiments for a flow rate of $175 \mathrm{~mL} / \mathrm{h}$ are depicted in Figure $3 \mathrm{i}$,ii for the hollow-fiber module and the stirred beaker, respectively. The tracer was selected so as to minimally adsorb onto the hol low fibers. This assumption was double checked by evaluating the total amount of tracer injected in the inlet stream with the total amount of tracer recovered at the outlet stream, and also by repeating some of the tracer experiments using glycerol. Such extra experiments consisted of the injection of quick pulses of tracer $(5.0 \mathrm{~mL}$ of a $210 \mathrm{~g} / \mathrm{L}$ aqueous solution of glycerol) at the appropriate inlet stream, col lection of samples from the appropriate outlet stream at constant time intervals, and assay of these samples for tracer concentration by measurement of their refractive index at $25{ }^{\circ} \mathrm{C}$ followed by conversion via a calibration curve previously prepared.

\section{Mathematical Modeling}

Hydrodynamics. Mathematical modeling of the data points obtained in the tracer experiments followed the classical (multipurpose) model of plug flow in the presence of longitudinal dispersion. The distribution of residence times, $E_{i}\{t\}$, may then be obtained by the equation
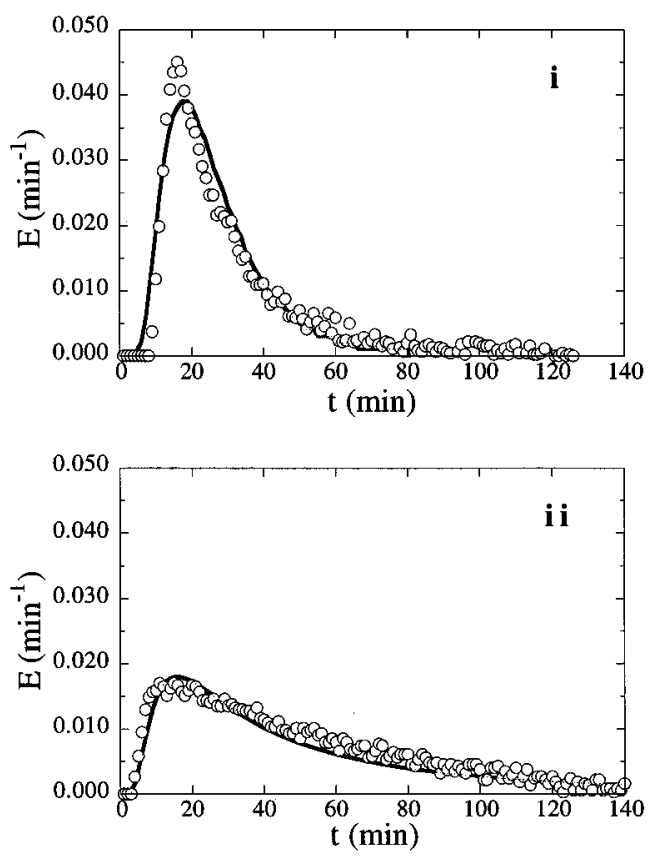

Figure 3. Response of the whole hollow-fiber module (i) and the stirred beaker (ii) to a pulse of tracer in the inlet stream (volumetric flow rate of $175 \mathrm{~mL} / \mathrm{h}$ ). The data points are represented by $\bigcirc$ and the theoretical fit by - .

$$
\begin{aligned}
& E_{i}\{t\}=\frac{C_{T, i}\{t\}}{\int_{0}^{\infty} C_{T, i}\{t\} d t}= \\
& \frac{1}{2} \sqrt{\frac{L_{i}^{2}}{\pi t D_{\text {lgt,i }}}} \exp \left\{-\frac{L_{i}^{2}\left(t-\frac{V_{i}}{Q}\right)^{2}}{4 t D_{\text {lgt }, i}\left(\frac{V_{i}}{Q}\right)^{2}}\right\}
\end{aligned}
$$

where subscript i becomes I, S, P, and $\mathrm{M}$ for the lumen side of the hollow-fiber module, the shell side of the hollow-fiber module, the whole hollow-fiber module, and the stirred beaker, respectively. Here $t$ is the time elapsed since startup of the tracer experiment, $C_{T, i}$ the tracer concentration at the appropriate outl et stream, $\mathrm{L}_{i}$ the average path length of the fluid element circulating through the system in question, $D_{\text {Igt,i }}$ the Iongitudinal dispersion of the tracer in the system, $V_{i}$ the volume of the system, and $\mathrm{Q}$ the volumetric flow rate through that system. Hence the lumped parameter $L_{i}{ }^{2} / D_{\text {lgt,i, }}$ which has dimensions of time, may be viewed as the time scale associated with longitudinal dispersion through the system under study, whereas the lumped independent variable $V_{i} / Q$, which has also dimensions of time, may be viewed as the time scale associated with convection through the same system.

Fits of the experimental data to the models entertained by eq 1 using nonlinear regression analyses have yielded the following estimates of $V_{i}: V_{1}=35.77 \pm 0.62 \mathrm{~cm}^{3}, V_{s}$ $=39.72 \pm 0.95 \mathrm{~cm}^{3}, \mathrm{~V}_{\mathrm{P}}=74.51 \pm 0.07 \mathrm{~cm}^{3}$, and $\mathrm{V}_{\mathrm{M}}=$ $191.04 \pm 0.04 \mathrm{~cm}^{3}$. The same fits have also yielded the following estimates for $L_{i}{ }^{2} / D_{\text {lgt, }}: L_{1}{ }^{2} / D_{\text {lgt,l }}=877.55 \pm 0.44$ $\mathrm{h}, \mathrm{L}_{\mathrm{s}}{ }^{2} / \mathrm{D}_{\text {lgt }, \mathrm{s}}=1519.5 \pm 6.7 \mathrm{~h}, \mathrm{~L}_{\mathrm{p}}{ }^{2} / \mathrm{D}_{\text {lgt }, \mathrm{P}}=2574.24 \pm 0.31$ $\mathrm{h}$, and $\mathrm{L}_{\mathrm{M}}{ }^{2} / \mathrm{D}_{\text {Igt, } \mathrm{M}}=1.68 \pm 0.54 \mathrm{~h}$. (It should be borne in mind that the confidence intervals of the parameters listed are provided as such by the postconvergence report generated by GREG (Stewart et al., 1992). Each marginal confidence interval is an indication of the effect of independent changes of the parameter in question upon the sum of squares of residuals of the theoretical model postulated relative to the experimental data generated, rather than an indication of the intrinsic variability of 
the experimental data as measured via, for example, performance of replicates: this latter variability may be orders of magnitude higher than the former.) The values of the lumen and the shell side hol dup volumes obtained from the tracer experiments are less than 15\% above their nominal counterparts; this is an indication that, within a reasonable experimental variability, dead volumes may be virtually neglected for modeling purposes. Furthermore, the volumes determined experimentally, in an independent fashion, for the lumen and the shell side add up to a total volume that is less than $2 \%$ above the volume determined experimentally for the whole hollow-fiber reactor; this is an indication that the space times of fluid in the inner and outer portions of the module are essentially equal to one another, and so, in terms of hydrodynamic behavior, the set of the inner and outer portions are equivalent to the hollow-fiber module considered as a whole. Finally, the volume of the beaker calculated from the tracer experiments is within $5 \%$ of the true holdup volume, which suggests that such a system is well approximated by a perfectly stirred model. On the other hand, the time scale associated with convection through the whole hollow-fiber module using the lowest possible flow rate tested (ca. $3 \mathrm{~mL} / \mathrm{h}$ ) is still more than 2 orders of magnitude lower than the time scale associated with longitudinal dispersion; this order of magnitude analysis indicates that dispersion is virtually nonexistent in view of the mean time period the fluid is allowed to remain in the module; therefore a true plug flow model appears to be a good approximation in attempts to model the hydrodynamic behavior of the hollow-fiber module. Recalling the useful length of the hollow fibers and the estimates of $L_{i}^{2} / D_{\text {lgt,i }}$, one obtains apparent Iongitudinal dispersion coefficients of $1.6 \times$ $10^{-8}, 9.7 \times 10^{-9}$, and $5.8 \times 10^{-9} \mathrm{~m}^{2} / \mathrm{s}$ for the lumen, the shell side, and the module, respectively, although no apparent physicochemical rationale could be found for the lower value of $D_{\text {Igt,P }}$ when compared with that for the lumen or the shell side. These values are ca. 1 order of magnitude higher than typical molecular diffusivities within liquids, an observation that was expected in view of the fact that the longitudinal dispersion results not only from the components of Brownian motion in the Iongitudinal direction but also from enhancement of the longitudinal concentration gradient brought about by the hydrodynamic flow pattern; further evidence supporting this rationale arises from the observation (results not shown) that Taylor dispersion effects (measured by $D_{\text {lgt,i }}$ ) generally increased with increasing flow rate Q. Conversely, the beaker exhibits a dispersion time scale which is on the same order of magnitude of the convection time scale even for flow rates as high as $200 \mathrm{~mL} / \mathrm{h}$ (the highest possible flow rate tested), and so it can be viewed for modeling purposes as a perfectly stirred system. As a consequence of the aforementioned fact that the flow rate in the lumen and in the shell side were independently adjusted, the space timethrough either side of the hollow fiber module was essentially the same, and so use of a single value for $\mathrm{V}_{\mathrm{i}} / \mathrm{Q}$ to describe the whole module was justified; this assumption was also backed up by realization that the residence time distributions of the hollowfiber module as a whole did not exhibit bimodal characteristics in any experiment performed (see, for example, Figure 3).

Adsorption. Within the time frame of the adsorption experiments, the adsorption process was tentatively assumed to be described by the following elementary (reversible) step:



Figure 4. Simplified representation of the system under study.

$$
\mathrm{P} \underset{\mathrm{k}_{-1}}{\stackrel{\mathrm{k}_{1}}{\rightleftarrows}} \mathrm{P}^{\#}
$$

where $P$ denotes a protein molecule in the bulk solution (in an essentially hydrophilic microenvironment), $\mathrm{P}^{\#} \mathrm{a}$ protein molecule in the liquid boundary layer at the immediate vicinity of the membrane (in an essentially hydrophobic microenvironment), $\mathrm{k}_{1}$ the kinetic constant associated with the adsorption of protein onto the membrane, and $\mathrm{k}_{-1}$ the kinetic constant associated with the desorption of protein from the membrane. This pseudoadsorption process is assumed to basically consist of a reversible alteration of the protein conformation upon change of the nature of the microenvironment, with concomitant lowering of the total Gibbs' free energy of the system (as required for a spontaneous process). The forward process is expected to be largely favored when compared with the reverse process in the case of lipases since these enzymes are especially hydrophobic.

For reasons detailed above, the hollow-fiber device and the beaker will be assumed to behave hydrodynamically as a plug flow reactor and as a continuous stirred tank reactor, respectively. Accordingly, the experimental setup may be viewed, in a schematic fashion, as depicted in Figure 4.

The balance to the continuous flow stirred tank can be written as

$$
\begin{gathered}
C_{P}\{t\}=C_{M}\{t\}+\frac{V_{M}}{Q} \frac{d C_{M}\{t\}}{d t} \\
t=0, C_{M}\{t\}=C_{0}
\end{gathered}
$$

where $C_{P}$ denotes the inlet concentration, $C_{M}$ the outlet concentration, and $\mathrm{C}_{0}$ the initial concentration of the protein in the stirred beaker.

The balance to the mobile phase (i.e., the supernatant) within the plug flow module can be written as

$$
\begin{gathered}
\frac{\partial C_{b}\{z, t\}}{\partial z}+\frac{\partial C_{b}\{z, t\}}{\partial t}+k_{1} C_{b}\{z, t\}-k_{-1} C_{a}\{z, t\}=0 \\
t=0,0 \leq z \leq L, C_{b}\{z, t\}=0 \\
t \geq 0, z=0, C_{b}\{z, t\}=C_{M}\{t\}
\end{gathered}
$$

where $v$ denotes the linear velocity of the mobile phase (assumed constant due to the plug flow assumption), $\mathrm{C}_{\mathrm{b}}$ the concentration of protein in the bulk of the supernatant, $z$ the longitudinal coordinate, $t$ the time elapsed after startup of the adsorption experiment, $\mathrm{C}_{\mathrm{a}}$ the concentration of protein adsorbed on the membrane, and $\mathrm{L}$ the length of the hollow-fiber module. The balance to the stationary phase (i.e., the membrane) in the plug flow module can be written as

$$
\frac{\partial C_{a}\{z, t\}}{\partial t}-k_{1} C_{b}\{z, t\}+k_{-1} C_{a}\{z, t\}=0
$$




$$
\mathrm{t}=0,0 \leq \mathrm{z} \leq \mathrm{L}, \mathrm{C}_{\mathrm{a}}\{\mathrm{z}, \mathrm{t}\}=0
$$

A solution of these differential balance equations using Laplace transforms is available as supporting information. The resulting equations for the model are as follows:

$$
\begin{aligned}
& \frac{\mathrm{C}_{\mathrm{M}}\{\mathrm{t}\}}{\mathrm{C}_{0}} \sim \frac{\mathrm{V}_{\mathrm{M}}}{\mathrm{aQs}_{1} \mathrm{~S}_{2}}+\left(1-\frac{\mathrm{V}_{\mathrm{M}}{ }^{3}}{\mathrm{aQ}\left(\mathrm{Q}+\mathrm{V}_{\mathrm{M}} \mathrm{S}_{1}\right)\left(\mathrm{Q}+\mathrm{V}_{\mathrm{M}} \mathrm{S}_{2}\right)}\right) \\
& \exp \left(-\frac{Q t}{V_{M}}\right)+\frac{V_{M}}{a s_{1}\left(Q+V_{M} s_{1}\right)\left(s_{1}-s_{2}\right)} \exp \left(s_{1} t\right)- \\
& \frac{V_{M}}{a s_{2}\left(Q+V_{M} s_{2}\right)\left(s_{1}-s_{2}\right)} \exp \left(s_{2} t\right)
\end{aligned}
$$

when the values of the parameters are such that $s_{1}$ and $\mathrm{s}_{2}$ take real values, and

$$
\begin{aligned}
& \frac{C_{M}\{t\}}{C_{0}} \sim \frac{V_{M}}{a Q\left(A^{2}+B^{2}\right)}+ \\
& \left(1-\frac{V_{M}{ }^{3}}{a Q\left(\left(A V_{M}-Q^{2}+B^{2} V_{M}{ }^{2}\right)\right.}\right) \exp \left(-\frac{Q t}{V_{M}}\right)+ \\
& \left\{\frac{V_{M}\left(\left(2 A \frac{V_{M}}{Q}-1\right) \cos (B t)-\frac{A+\left(B^{2}-A^{2}\right) \frac{V_{M}}{Q}}{B} \sin (B t)\right)}{a Q\left(A^{2}+B^{2}\right)\left(\left(A^{2}+B^{2}\right)\left(\frac{V_{M}}{Q}\right)^{2}-2 A \frac{V_{M}}{Q}+1\right)}\right\} \\
& \exp (-A t)
\end{aligned}
$$

when the values of the parameters are such that $s_{1}$ and $\mathrm{s}_{2}$ take complex values (the symbols $\mathrm{a}, \mathrm{A}, \mathrm{B}, \mathrm{s}_{1}$, and $\mathrm{s}_{2}$ denote constants and are defined in the supporting information). Inspection of eqs 6 and 7 allows one to write that

$$
\lim _{t \rightarrow \infty} \frac{C_{M}\{t\}}{C_{0}} \equiv \frac{C_{M, \infty}}{C_{0}}=\frac{V_{M}}{c Q}
$$

(where c denotes a constant and is defined in the supporting information) or, equivalently,

$$
\lim _{t \rightarrow \infty} C_{a d s}\{t\} \equiv \frac{\hat{V}\left(C_{0}-C_{M, \infty}\right)}{\hat{A}}=\frac{\hat{V} C_{0} V_{P}\left(1+\frac{k_{1}}{k_{-1}}\right)}{\hat{A}\left(V_{M}+V_{P}\left(1+\frac{k_{1}}{k_{-1}}\right)\right)}
$$

where $\mathrm{C}_{\text {ads }}$ denotes the concentration of protein adsorbed on the hollow fibers at any given time, $\hat{V}$ the total volume of supernatant solution, $\hat{A}$ the total outer surface membrane area available for adsorption, and $\mathrm{C}_{\mathrm{M}, \infty}$ the equilibrium concentration of protein in the supernatant solution.

\section{Statistical Analysis}

The hydrodynamic and adsorption models were fitted to the corresponding experimental data via nonlinear regression analyses, using a general regression package for nonlinear parameter estimation that uses as the objective function the minimization of the sum of squares of the residuals between the values predicted by the model and the experimental data-GREG (Stewart et al ., 1992). The results of typical fits are depicted as solid lines in Figures $3 i$,ii and 2 , respectively.

Since the data generated pertaining to every lipase includes replications (corresponding to the repetitions of the adsorption experiments at a given flow rate for various initial concentrations of protein on the supernatant solution), it was possible to perform tests of lack of fit of the expectation functions entertained in this communication, i.e. eq 6 or 7. Such analysis (which is based on the fact that the replication subspace is al ways orthogonal to the subspace containing the averages and the expectation function) (Bates and Watts, 1988) is based on the comparison of the ratio of the lack of fit mean square over the replication mean square with the appropriate value in the $\mathrm{F}$ table. Implementation of such a type of analysis using the data plotted in Figure 2 is depicted in Table 1.

The best estimates (and associated marginal inference intervals as provided by the postconvergence report generated by GREG) of the adsorption/desorption parameters are tabulated in Table 2 for all lipases assayed. The values of the amount of protein adsorbed at equilibrium conditions extrapolated from the proposed model using the best parameter estimates are tabulated in Table 3 in the form of ranges that encompass the four initial concentrations of crude lipase in the supernatant solution considered (long-term experiments for some of the lipases and initial supernatant concentrations indicated a good correlation of such theoretical extrapolations with physical evidence). In this table are also included, for comparative purposes, values reported in the literature pertaining to adsorption of lipases.

\section{Discussion}

The reversible model postulated for the lipase adsorption based on eq 2 apparently holds for the time frame of the adsorption experiments performed. However, if the hollow-fiber module is washed with plain buffer after the adsorption experiments, the amount of protein in the effluent stream will tend rapidly to zero and virtually no protein will be detected after a long time on the stream, although a considerable amount of protein will be readily recovered if the plain buffer is replaced by ethanol (results not shown). This observation, which is similar to a previous report by Malcata et al. (1991) and seems to contradict the postulated reversibility of adsorption of lipase, may probably be explained by the assumption that the enzyme molecules in the (hydrophobic) boundary layer (i.e., $\mathrm{P \#}$ ), which are essentially folded in the beginning and thus able to contact the surface at only one site (or, at most, at a very limited number of sites), begin to slowly unfold upon contact as time on the stream elapses, thus al lowing more of their surface to come into contact with the polymer and consequently creating a multiplicity of binding sites; although breakage of contact at a single site is quite feasible (which is consistent with reversible adsorption), desorption via simultaneous detachment of the protein segments from all binding sites is an extremely improbable event (which is consistent with irreversible adsorption).

It may be argued that the longitudinal Péclet number for the hollow-fiber module (defined as the ratio of the time scale associated with longitudinal dispersion, $L_{p}{ }^{2} /$ $D_{\text {lgt, }}$, to the time scale associated with convection, $V_{p} / Q$ ) associated with, say, the conditions underlying Figure 3 is not sufficiently high to warrant assumption of a plug flow system, whereas the Péclet number for the stirred 
Table 1. Lack of Fit Analysis for the Model Proposed with Respect to the Adsorption Data Pertaining to the 10 Lipases Screened

\begin{tabular}{|c|c|c|c|c|c|c|}
\hline lipase origin & source & NDFa & $\mathrm{SS}^{\mathrm{b}}$ & $\mathrm{MSc}^{\mathrm{C}}$ & F ratio ${ }^{d}$ & std F ratio \\
\hline \multirow[t]{2}{*}{ C. lipolytica } & $\begin{array}{l}\text { lack of fit } \\
\text { replications }\end{array}$ & $\begin{array}{r}9 \\
29\end{array}$ & $\begin{array}{l}0.027996 \\
0.032274\end{array}$ & $\begin{array}{l}0.0031107 \\
0.0011129\end{array}$ & 2.795196 & 3.100 \\
\hline & residuals & 38 & 0.060270 & & & \\
\hline \multirow[t]{2}{*}{ A. niger } & $\begin{array}{l}\text { lack of fit } \\
\text { replications }\end{array}$ & $\begin{array}{r}9 \\
24\end{array}$ & $\begin{array}{l}0.036630 \\
0.056587\end{array}$ & $\begin{array}{l}0.0040700 \\
0.0023578\end{array}$ & 1.726204 & 3.260 \\
\hline & residuals & 33 & 0.093216 & & & \\
\hline \multirow[t]{2}{*}{ G. candidum } & $\begin{array}{l}\text { lack of fit } \\
\text { replications }\end{array}$ & $\begin{array}{l}12 \\
18\end{array}$ & $\begin{array}{l}0.028884 \\
0.073753\end{array}$ & $\begin{array}{l}0.0024070 \\
0.0040974\end{array}$ & 0.587440 & 3.370 \\
\hline & residuals & 30 & 0.102637 & & & \\
\hline \multirow[t]{2}{*}{ R. delemar } & $\begin{array}{l}\text { lack of fit } \\
\text { replications }\end{array}$ & $\begin{array}{r}9 \\
31\end{array}$ & $\begin{array}{l}0.027025 \\
0.097484\end{array}$ & $\begin{array}{l}0.0030028 \\
0.0031446\end{array}$ & 0.954896 & 3.057 \\
\hline & residuals & 40 & 0.124509 & & & \\
\hline \multirow[t]{2}{*}{ H. lanuginosa } & $\begin{array}{l}\text { lack of fit } \\
\text { replications }\end{array}$ & $\begin{array}{r}9 \\
33\end{array}$ & $\begin{array}{l}0.019805 \\
0.147685\end{array}$ & $\begin{array}{l}0.0022006 \\
0.0044753\end{array}$ & 0.491713 & 3.021 \\
\hline & residuals & 42 & 0.167490 & & & \\
\hline \multirow[t]{2}{*}{ P. roquefortii } & $\begin{array}{l}\text { lack of fit } \\
\text { replications }\end{array}$ & $\begin{array}{r}9 \\
30\end{array}$ & $\begin{array}{l}0.032461 \\
0.039825\end{array}$ & $\begin{array}{l}0.0036068 \\
0.0013275\end{array}$ & 2.717024 & 3.075 \\
\hline & residuals & 39 & 0.072286 & & & \\
\hline \multirow[t]{2}{*}{ P. camembertii } & $\begin{array}{l}\text { lack of fit } \\
\text { replications }\end{array}$ & $\begin{array}{l}11 \\
28\end{array}$ & $\begin{array}{l}0.020927 \\
0.049120\end{array}$ & $\begin{array}{l}0.0019024 \\
0.0017543\end{array}$ & 1.084463 & 2.965 \\
\hline & residuals & 39 & 0.070046 & & & \\
\hline \multirow[t]{2}{*}{ M. javanicus } & $\begin{array}{l}\text { lack of fit } \\
\text { replications }\end{array}$ & $\begin{array}{l}11 \\
28\end{array}$ & $\begin{array}{l}0.008005 \\
0.114370\end{array}$ & $\begin{array}{l}0.0007278 \\
0.0040846\end{array}$ & 0.178167 & 2.965 \\
\hline & residuals & 39 & 0.122375 & & & \\
\hline \multirow[t]{2}{*}{ C. cylindracea } & $\begin{array}{l}\text { lack of fit } \\
\text { replications }\end{array}$ & $\begin{array}{l}14 \\
34\end{array}$ & $\begin{array}{l}0.041729 \\
0.163592\end{array}$ & $\begin{array}{l}0.0029807 \\
0.0048115\end{array}$ & 0.619486 & 2.675 \\
\hline & residuals & 48 & 0.205321 & & & \\
\hline \multirow[t]{2}{*}{ R. oryzae } & $\begin{array}{l}\text { lack of fit } \\
\text { replications }\end{array}$ & $\begin{array}{r}9 \\
27\end{array}$ & $\begin{array}{l}0.025820 \\
0.043152\end{array}$ & $\begin{array}{l}0.0028689 \\
0.0015982\end{array}$ & 1.795019 & 3.160 \\
\hline & residuals & 36 & 0.068972 & & & \\
\hline
\end{tabular}

a No. of degrees of freedom. ${ }^{b}$ Sum of squares. ${ }^{c}$ Mean square, SS/NDF. ${ }^{\text {F }}$ Fisher ratio, (MS for lack of fit)/(MS for replication) e $F\left(N D F_{\text {lack of fit; }}\right.$ NF D replications; $\left.5 \%\right)$.

Table 2. Parameter Estimates and Associated Marginal Inference Intervals for the Parameters of the Model Fitted to the Data Pertaining to Adsorption of the Various Lipases

\begin{tabular}{lccc}
\hline source of lipase & trade name & $\mathrm{k}_{1} \pm 2 \sigma\left(\mathrm{h}^{-1}\right)$ & $\mathrm{k}_{-1} \pm 2 \sigma\left(\mathrm{h}^{-1}\right)$ \\
\hline C. lipolytica & L5 & $4.962 \pm 2.920$ & $0.501 \pm 0.404$ \\
A. niger & A6 & $4.444 \pm 2.806$ & $0.371 \pm 0.363$ \\
G. candidum & GC4 & $4.022 \pm 2.399$ & $0.659 \pm 0.519$ \\
R. delemar & D20 & $3.961 \pm 2.113$ & $0.640 \pm 0.452$ \\
H. lanuginosa & CE 10 & $3.413 \pm 1.482$ & $0.581 \pm 0.342$ \\
P. roquefortii & R10 & $3.233 \pm 1.107$ & $0.769 \pm 0.338$ \\
P. camembertii & G50 & $3.022 \pm 0.625$ & $0.367 \pm 0.120$ \\
M. javanicus & M10 & $2.913 \pm 0.727$ & $0.378 \pm 0.141$ \\
C. cylindracea & AY30 & $2.908 \pm 0.762$ & $0.381 \pm 0.153$ \\
R. oryzae & F-AP15 & $1.981 \pm 0.571$ & $0.733 \pm 0.264$
\end{tabular}

beaker (defined as the ratio of the time scale associated with longitudinal dispersion, $L_{M}{ }^{2} / D_{\text {lgt, } M}$, to the time scale associated with convection, $V_{M} / Q$ ) in the same situation is not sufficiently low to warrant assumption of a perfectly stirred system. However, a posteriori analyses of the goodness of the fits based on the simplified hydrodynamic behaviors (see Table 1) have not provided evidence of lack of fit for any of the lipases assayed. On the other hand, the residuals of such models with respect to the data obtained for each lipase studied plotted against the percentiles of a normal distribution and against the data themselves (not shown) do not exhibit biased trends, which provides further indication that the deviations from the models are normally distributed with constant variances, respectively. Hence, no statistically apparent reason exists to doubt of the form of the model proposed in view of the data sets available. It is noteworthy to remember here that "all models are wrong; the practical question is how wrong do they have to be to not be useful" (Box and Draper, 1987). Since no lack of fit is found, the estimate of the variance for the whole set of data generated for each lipase should be based on the residual mean square, and hence, the replication and lack of fit sums of squares and degrees of freedom should be recombined in order to give an estimate with the largest number of degrees of freedom (so as to provide the most reliable parameter estimates and expected value confidence regions).

A further point of possible concern pertains to the fact that the adsorption of lipase is, by definition, an interfacial phenomenon, and so radial concentration gradients may build up even though the (nonadsorbable) tracer experiments suggest that the aqueous fluid is in essentially plug flow. Order of magnitude analyses indicate that the time scale associated with molecular transport in the radial direction is ca. $r_{1}^{2} / D_{r d, p}$ (where $r_{1}$ is the internal radius of the hollow fibers and $D_{r d, P}$ is the radial diffusivity of protein in the aqueous solution), whereas the time scale associated with the process of adsorption of protein on the vicinity of the poly(propylene) surface 
Table 3. Equilibrium Values for the Amount of Protein Adsorbed from Preparations of Lipase

\begin{tabular}{lcllll}
\hline source of lipase & $\mathrm{C}_{\text {ads }}\left(\mathrm{mg}_{\text {protein }} / \mathrm{m}_{\text {membrane }}^{2}\right)$ & carrier & $\mathrm{pH}$ & $\mathrm{T}\left({ }^{\circ} \mathrm{C}\right)$ & ref \\
\hline A. niger & 65.5 & poly(propylene) & 7.0 & 35 & Malcata et al. (1991) \\
A. niger & 41.4 & poly(propylene) & 7.0 & 27 & Malcata et al. (1992a) \\
A. niger & $39.7-109.2$ & poly(propylene) & 7.0 & 40 & this work \\
C. cylindracea & $36.3-102.1$ & poly(propylene) & 7.0 & 40 & this work \\
C. rugosa & 38.8 & cellulose & n.a. & 30 & Geluk et al. (1992) \\
C. rugosa & 0.2 & cellulose & $3.6-5.6$ & 30 & Pronk et al. (1988) \\
C. lipolytica & $43.2-137.3$ & poly(propylene) & 7.0 & 40 & this work \\
G. candidum & $34.8-97.2$ & poly(propylene) & 7.0 & 40 & this work \\
H. lanuginosa & $27.0-98.8$ & poly(propylene) & 7.0 & 40 & this work \\
M. javanicus & $39.7-111.0$ & poly(propylene) & 7.0 & 40 & this work \\
P. camembertii & $28.5-99.7$ & poly(propylene) & 7.0 & 40 & this work \\
P. roquefortii & $41.7-76.6$ & poly(propylene) & 7.0 & 40 & this work \\
R. oryzae & $28.4-66.9$ & poly(propylene) & 7.0 & 40 & this work \\
R. delemar & $27.1-91.4$ & poly(propylene) & 7.0 & 40 & this work \\
Rhizopus sp. & $9.7-12.2$ & poly(tetrafluoroethylene) & 8.0 & 37 & Rucka et al. (1989) \\
Rhizopus sp. & $2.8-3.4$ & poly(vinyl chloride) & 8.0 & 37 & Rucka and Turkiewic (1990)
\end{tabular}

is ca. $1 / k_{1}$. Using the common assumption that the diffusivity of a solute in a liquid is on the order of $10^{-9}$ $\mathrm{m}^{2} / \mathrm{s}$ and recalling the internal radius of the fibers (120 $\mu \mathrm{m})$, then the time scale associated with molecular transport is on the order of $15 \mathrm{~s}$. On the other hand, values of $\mathrm{k}_{1}$ ranging from 1.98 to $4.96 \mathrm{~h}^{-1}$ (see Table 2) yield time scales for adsorption on the order of 900-1800 s. Ther efore, the time taken up by adsorption is roughly 2 orders of magnitude larger than that taken up by plain diffusion, which means that virtually no concentration gradients exist in the radial direction.

When attempting to fit postulated rate expressions to experimental data on substrate concentrations generated via some kind of reactor setup, the parameters arising from assumptions on the hydrodynamics (i.e., those directly related to the form of the mass balances) and those arising from assumptions on the mechanism of reaction (i.e., those related to the rate expression itself) are often estimated simultaneously. Using this approach, one may by chance stumble into a combination of values for the parameters (viz. $L_{i}{ }^{2} / D_{\text {Igt,i }}, V_{i} / Q, k_{1}$, and $\mathrm{k}_{-1}$ ) that provide a good fit yet are physically inconsistent. This problem was avoided in the approach followed in this work because the parameters describing the hydrodynamics (viz. $L_{i}{ }^{2} / D_{\text {Igt,i }}$ and $V_{i} / Q$ ) were fitted using a set of tracer experiments, whereas the parameters describing the rate expression (viz. $k_{1}$ and $k_{-1}$ ) were fitted using a set of adsorption experiments, and the two sets of experiments were run independently.

From inspection of Table 2, one notices that every t-ratio (or ratio of the confidence interval to the estimate of the corresponding parameter) for the desorption kinetic constant $\left(k_{-1}\right)$ is in general much closer to unity than that for the adsorption kinetic constant $\left(k_{1}\right)$ for all lipases. Numerical checks for sensitivity indicated that this fact did not arise significantly from the dependence of the model depicted by eqs 6 and 7 on the estimated value of $\mathrm{V}$ in eq 1, but was rather due to a relatively larger scatter of the data points at long experiment times (the region which more directly affects the estimate of $k_{-1}$ ) when compared with the scatter at short experiment times (the region which more directly affects the estimate of $k_{1}$ ). In all cases, however, the null hypothesis is rejected at the $5 \%$ confidence level. If the process of adsorption of lipase were truly irreversible and first order, then the time required for $50 \%$ of the total adsorption of lipase to be completed (i.e., $\mathrm{t}_{1 / 2}=\ln \{2\} / \mathrm{k}_{1}$ ) would range from 8 to 20 min (see Table 2). Inspection of Figure 2 indicates that such a range is actually ca. 40-65 $\mathrm{min}$, and such differences emphasize the effect of the reversible firstorder desorption step.

With respect to the (extrapolated) equilibrium values for the amounts of protein adsorbed from crude prepara- tions of lipase in Mcllvaine buffer (see Table 3 ), it is remarkable that the ranges obtained in this research effort include the values reported in the literature and achieved for similar types of hydrophobic supports. Hydrophilic supports experimented by other researchers (e.g., cellulose, poly(tetrafluoroethylene), and poly(vinyl chloride)) give rise to saturation concentrations of lipase well below the ranges obtained for hydrophobic supports. These observations can be interpretated in light of the assumptions underlying the development of our mathematical model, viz. that adsorption follows a preliminary step of alteration of the conformation of the proteins including lipase in the vicinity of hydrophobic interfaces. (It should be remembered here that all that was measured was adsorption of protein from crude lipase preparations using a BSA equivalent, and so proteins other than lipase were also assayed; however, results not shown indicate clearly that the hollow fiber module did acquire lipolytic activity following every adsorption experiment, which indicates that lipase was one of the proteins actually adsorbed.)

As far as our knowledge goes, the present work is somewhat pioneering in the area of comprehensive description of the kinetics of adsorption of lipases onto hollow-fiber membranes. It allows, for each lipase (not necessarily limited to the commercial lipases tested), the prediction of the adsorption time required by a desired fraction of the maximum membrane coverage (say, 90\%) to be achieved. This prediction is relevant because the adsorption step takes place prior to utilization of a hollow-fiber module as a lipase bioreactor in the performance of hydrolysis or interesterification relations, and the dead time required by such immobilization step must be taken into account when designing or modeling enzyme-reaction systems, especially on the commercial scale.

\section{Acknowledgment}

The lipases utilized were a gift from AMANO. Partial funding for the research was provided through grants and/or fellowships by FLAD (Portuguese American Foundation for Development-Project Lipase-catalyzed interesterification of butterfat with olive oil, J NICT (Portuguese Board of Scientific and Technological Research-BD 2091/92-I F), and Institut CANDI A (Project Modification de la matiére grasse par des lipases immobilisées sur un réacteur à membrane). The authors are grateful to Prof. Henry Bungay (Rensselaer Polytechnic Institute, Troy, $\mathrm{NY}$ ) for his critical suggestions concerning this communication.

Supporting Information Available: Text describing the mathematical derivation of eqs 6 and 7 from eqs 3-5 using 
Lapace transform and Taylor expansion methods (3 pages). Ordering information is given on any current masthead page.

\section{Literature Cited}

Bailey, J . E.; Ollis, D. F. Biochemi cal Engineering F undamentals; McGraw-Hill: New York, NY, 1986.

Bates, D. M.; Watts, D. G. Nonlinear Regression Analysis and its Applications; Wiley Interscience: New York, NY, 1988.

Box, G. E. P.; Draper, N. R. Empirical mode-building and response surfaces; J ohn Wiley \& Sons: New York, NY, 1987.

Brady, C.; Metcalfe, L.; Slaboszewski, D.; Frank, D. Lipase immobilised on a hydrophobic, microporous support for the hydrolysis of fats. J. Am. Oil Chem. Soc. 1988, 65, 917.

Dawson, R. M. C.; Elliott, W. H.; Elliott, D. C.; J ones, K. M. Data for biochemical research; Oxford Science Publications: Oxford, U.K.; 1969; p 427.

Geluk, M. A.; Norde, W.; Van Kalsbeek, H. K. A. I.; Van't Riet, $K$. Adsorption of lipase from Candida rugosa on cellulose and its influence on lipolytic activity. Enz. Microb. Technol. 1992, 14, 748.

Hoq, M. M.; Koike, M.; Yamane, T.; Shimizu, S. Continuous hydrolysis of olive oil by lipase in microporous hydrophobic hollow-fi ber bioreactor. Agric. Biol. Chem. 1985a, 49, 3171.

Hoq, M. M.; Tagami, H.; Yamane, T.; Shimizu, S. Some characteristics of continuous glyceride synthesis by lipase in a microporous hydrophobic membrane bi oreactor. Agric. Biol. Chem. 1985b, 49, 335.

Hoq, M. M.; Yamane, T.; Shimizu, S. Continuous hydrolysis of olive oil by lipase in microporous hydrophobic membrane bi oreactor. J . Am. Oil Chem. Soc. 1985c, 62, 1016.

Malcata, F. X.; Hill, C. G.; Amundson, C. H. Use of a lipase immobilized in a membrane reactor to hydrolyze the glycerides of butteroil. Biotechnol. Bioeng. 1991, 38, 853-868.

Malcata, F. X.; Garcia, H. S.; Hill, C. G.; Amundson, C. H. $\mathrm{Hydrolysis}$ of butteroil by immobilized lipase using a hollowfiber reactor: Part I. Lipase adsorption studies. Bi otechnol. Bi oeng. 1992a, 39, 647.

Malcata, F. X.; Hill, C. G.; Amundson, C. H. Hydrolysis of butteroil by immobilized lipase using a hollow-fiber reactor: Part II. Uniresponse kinetic studies. Biotechnol. Bioeng. 1992b, 39, 984.

Malcata, F. X.; Hill, C. G.; Amundson, C. H. Hydrolysis of butteroil by immobilized lipase using a hollow-fiber reactor: Part III. Multiresponse kinetic studies. Bi otechnol. Bioeng. 1992c, 39, 1002.

Malcata, F. X.; Hill, C. G.; Amundson, C. H. Hydrolysis of butteroil by immobilized lipase using a hollow-fiber reactor: Part IV. Effects of temperature. Biotechnol. Bioeng. 1992d, 39, 1097.
Malcata, F. X.; Hill, C. G.; Amundson, C. H. Hydrolysis of butteroil by immobilized lipase using a hollow-fiber reactor. Part V: Effects of pH. Biocatalysis 1993a, 7, 177.

Malcata, F. X.; Hill, C. G.; Amundson, C. H. Hydrolysis of butteroil by immobilized lipase using a hollow-fiber reactor. Part $\mathrm{VI}$ : Multiresponse effects of temperature and $\mathrm{pH}$. Biocatalysis 1993b, 8, 201.

Masoom, M.; Mateen, A.; Townshend, A. The technology and analytical applications of immobilized enzymes. J . Chem. Soc. Pak. 1989, 11, 81.

Pronk, W.; Kerkhof, P. J . A. M.; Van Helden, C.; Van't Riet, K. The hydrolysis of triglycerides by immobilized lipase in a hydrophilic membrane reactor. Biotechnol. Bioeng. 1988, 32, 512.

Robyt, J . F.; White, B. J . Biochemical Techniques-Theory and Practice; Waveland: Illinois, 1990.

Rouxhet, P. G. Immobilization of biocatalysts and interfacial chemistry. Ann. N.Y. Acad. Sci. 1990, 613, 265.

Rucka, M.; Turkiewicz, B.; Tomaszewska, M.; Chlubek, N. Hydrolysis of sunflower oil by means of hydrophobic membrane with lipolytic activity. Biotechnol. Lett. 1989, 11, 167.

Rucka, M.; Turkiewicz, B. Ultrafiltration membranes as carriers for lipase immobilization. Enz. Microb. Technol. 1990, 12, 52.

Sarda, L.; Desnuelle, P. Action de la lipase pancréatique sur les esters en émulsion. Biochim. Biophys. Acta 1958, 30, 513.

Stewart, W. E.; Caracotsios, M.; Sørensen; J . P. GREG Software Package Documentation. University of Wisconsin: Madison, WI, 1992.

Taylor, F .; Panzer, C. C.; Craig, J . C.; O'Brien, D. J . Continuous hydrolysis of tallow with immobilized lipase in a microporous membrane. Biotechnol. Bioeng. 1986, 28, 1318.

Tramper, J . Organic synthesis using immobilized enzymes. In Solid Phase Biochemistry: Analytical and Synthetic Aspects; Scouten, W. H., Ed.; J ohn Wiley \& Sons: New York, 1983; $p$ 393.

Van der Padt, A.; E dema, M. J .; Sewalt, J . J . W.; Van't Riet, K. Enzymatic acylglycerol synthesis in a membrane bioreactor. J . Am. Oil Chem. Soc. 1990, 67, 347.

Yamane, T.; Hoq, M. M.; Shimizu, S. Kinetics of continuous hydrolysis of olive oil by lipase in microporous hydrophobic membrane bioreactor. J . J pn. Oil Chem. Soc. 1986, 10. 